\title{
Los dioses tienen sed: reflexión sobre Proyecto Ruanda de Alfredo Jaar
}

\author{
The gods are thirsty: essay on \\ Alfredo Jaar's Rwanda Project
}

\author{
David Moriente \\ Universitat Pompeu Fabra, Barcelona \\ david.moriente@hotmail.com
}

- Resumen - El objetivo del artículo es reflexionar sobre el procedimiento de gestión icónica utilizado por Alfredo Jaar (Santiago, 1956) dentro del contexto de las obras derivadas de Rwanda Project, un monumental trabajo realizado desde 1994 que enuncia los desastres causados por la violencia inhumana en el genocidio de Ruanda. La intención es comprender los mecanismos retóricos usados por Jaar -mise-eninvisibilité- dirigidos a la conciencia visual del espectador a través de la ocultación total o parcial de la imagen, la narración secuencial y procedimientos escenográficos establecidos en instalaciones de gran formato o la evocación literaria.

Palabras clave: Alfredo Jaar, arte contemporáneo, instalación, fotografía, estrategias de invisibilidad en el arte, cultura visual.

Abstract . The following article focuses on the iconic procedures used by Alfredo Jaar (Santiago, 1956) in his huge artpiece The Rwanda Project, a work-in-progress exhibited since 1994, which states the disaster of heartless violence in Rwanda's genocide. Our objective is to understand the rethoric processes in Jaar's work, its functions and how they are adressed to the visual consciousness of the audience by means of total or partial concealing of images, using sequential narratives or scenographic appeal on great scale installations, or by evocation of literary memories. Keywords: Alfredo Jaar, Contemporary Art, Installation Art, Photography, Art Strategies for Invisibility, Visual culture. 
La premisa inicial se asienta en que el trabajo del artista y arquitecto Alfredo Jaar está inscrito, desde la segunda mitad de la década de los noventa, en un modelo de representación donde gran parte de su fuerza expresiva radica, de manera paradójica, en la oclusión y ocultación de los contenidos visuales. Es entre las décadas de 1980 y 1990 que este tipo de obras comienzan a proliferar y a generalizarse dentro de la práctica artística contemporánea, utilizando el citado recurso de obstrucción visual para denunciar a través de lo invisible (lo que-no-se-puede-ver o lo que-no-debeser-visto) prácticas políticas, económicas, punitivas, sociales o represivas en clave de justicia transicional, historia poscolonial, testimonios de memoria oral $\mathrm{u}$ otros protocolos de análogas cualidades. Así, en nombres como los de Marcelo Brodsky, Hans Haacke, Santiago Sierra o el mismo Alfredo Jaar se perciben categorías similares de uso de la emancipación de lo invisible o lo irrepresentable; aunque sin duda este tipo de gestión iconográfica está mucho más extendida en la práctica documental: el ejemplo paradigmático proviene del polémico film de Claude Lanzmann Shoah (1985), que confronta los relatos y los recuerdos de víctimas y verdugos en los campos nazis a través de sus casi diez horas de metraje.

Ahora bien, de todas estas obras se puede extraer un intenso dilema entre dos fuerzas radicalmente opuestas y diferenciadas. En primer lugar, debe distinguirse la cuestión del poder/deber frente a la voluntad de saber/conocer y su inmediato reverso negativo: es decir, lo que debe/puede/tiene que ser visto es una compleja amalgama de diversas graduaciones morales que definen si se posee o no la potestad para construir o reinterpretar una imagen (con independencia de su grado de descripción o de evocación) sobre determinado acontecimiento caracterizado por su excepcional irrupción violenta. Resulta obvio que lo-inconcebible-Auschwitz -o si se prefiere todas las características combinadas de topos, locus, evento, entelequia, singularidad histórica- es hacia donde se dirigen de un modo u otro las llamadas éticas de atención: parece necesario saber la verdad pero esta solamente lo es, si y solo si, cuando está encarnada en el testigo. Otra de las diferencias entre saber y poder se plasma en la dificultad de conjugar la transparencia de los enunciados junto a su anverso opaco en contextos que necesitan una limitación o unos franqueos precisos: en definitiva, ¿dónde se sitúa (o debe situarse) la frontera ética en el ejercicio estético? Una pregunta de la que derivan infinidad de respuestas, tantas como artistas y conciencias ideológicas.

En lo que concierne al estudio del caso concreto de Alfredo Jaar, nos centramos en algunos ejemplos procedentes de la obra nodriza Rwanda Project. No obstante, su producción de juventud en el marco chileno está bien estudiada por expertos como Adriana Valdés, empero ya en aquella época muestra inquietudes sobre las relaciones de poder y la intervención en la conciencia del ciudadano que emergerán reforzadas en años ulteriores. Nuestra elección por Rwanda Project está motivada por el problema que plantea interpretarla como protocolo de no-representación cuya expresión se asienta en la evocación, el fuera de campo y el descoyuntamiento 
radical de cualquier significado objetivo de la fotografía. Según las tesis de La cámara lúcida -el paso de lo analógico a lo digital las ha invalidado definitivamenteel registro de un momento fijado desarrolla una fuerte conexión con el lugar, con un haber estado ahí del que habla Barthes, con el testimonio; sin embargo en Jaar, como veremos en los trabajos originados por su viaje a Ruanda, se despliega una minuciosa táctica de ocultación, derivada en una suerte de imagen invisible, que si bien presenta al artista como testigo también disuelve su yo junto a los canales de representación visual: existe una férrea voluntad de inscribir una imagen mental en el espectador a través de las evocaciones sugeridas de un acontecimiento en lugar de su representación icónica. Porque como intentaremos argumentar, Jaar no solamente propone un discurso alejado de la descripción literal del horror-tromografía lo denominamos- sino que su obra es un soporte crítico al estereotipo de África creado por y para los occidentales, en definitiva, del contexto geopolítico de toda una constelación de estados fallidos, a decir del pensador Noam Chomsky.

La misión que se impone Jaar inmediatamente después de la pacificación (durante algunos meses persistieron aislados repuntes de violencia) del conflicto en Ruanda, «el país de las mil colinas», es poco menos que una tarea titánica que abarca los procesos del ver y el mirar: observar, dirigir la atención, registrar, percibir, reconocer, son componentes de la trama visual. Así, gracias al objetivo de la cámara el artista (o el reportero en su caso) puede aislarse, figuradamente, de las ondas de choque que lo envuelven: Didi-Huberman lo expresa de modo certero en tanto la «doble distancia», construida mediante el pensamiento benjaminiano (41-45). En Ruanda, la situación social y política sobrepasó el límite de lo verosímil y explotó en una supernova visual: ni el ojo ni el cerebro se habían diseñado para discernir los contornos de esa crueldad ilegible. ¿Estaba el artista preparado para dar testimonio o comprender siquiera lo que se localiza en esa dimensión de caos puro? No. Prueba de ello es que dos años después de haber tomado unas tres mil fotografías en el lapso de dos meses, todavía no sabía qué hacer con ellas. Los eventos de Ruanda reclamaban diferenciarse de imágenes que ya formaban parte del patrimonio visual y el inconsciente colectivo universal como Self-immolation of Thich Quang Duc (Malcolm Browne, 1963), Murder of a Vietcong by Saigon police chief (Eddie Adams, 1968) o Napalm Girl (Nick Ut, 1972); en este sentido, Rwanda Project de Jaar responde a estas expectativas con una demorada y compleja investigación, repleta de numerosos ensayos, cuyo subtexto es el enunciado de la disyuntiva ético-estética sobre cómo manifestar lo irrepresentable.

\section{HORROR TRAS AUSCHWITZ: RUANDA (O LA SHOAH AFRICANA)}

Para comprender lo que vio Jaar, y su intento de asimilación y proyección, resulta ineludible aproximarse a la naturaleza de lo ocurrido durante aquella primavera de 1994 en Ruanda, donde en poco más de tres meses murieron asesinadas un millón de personas de una población de ocho millones. A esta cifra hay que añadir todos 
los que perecieron a causa de las mutilaciones, hambre y epidemias en los campos de refugiados de Zaire, Uganda o Tanzania. Un millón de muertos, el mismo número de víctimas que durante tuvo los tres años en que se extendió la guerra civil española. Un millón de personas. Diez mil al día, lo que equivale a decir que los indefensos morían al ritmo de un individuo cada ocho segundos; una cadencia que sobrepasa el exterminio industrializado del protocolo Endlösung ejecutado por los nazis a partir de 1941.

Los sucesos acaecidos en Ruanda superaron cualquier expectativa racional de juicio. En especial por el desbordamiento de imágenes que los medios, sobre todo los televisivos, se empeñaron en revelar tras la masacre, mezclando obstinada y paradójicamente la náusea y la anestesia. El genocidio de Ruanda fue, como la mayoría de los estudiosos acuerdan, una detonación de los residuos de décadas de acción colonial cuyos efectos tóxicos han sido devastadores para la región. De la misma manera que otros países africanos, a finales del siglo xIx, los ruandeses vieron afectados sus territorios y sus identidades debido a la política de apropiación de las potencias coloniales -principalmente Francia, Alemania, Italia y Bélgica- que se repartían el continente trazando líneas rectas sobre el mapa, construyendo fronteras donde antes no existían y unificando espacios -separados antes por cosmovisiones y tradiciones más que por la etnia y el carácter tribal, categorías acentuadas por los dominadores europeos- en nuevas naciones ex nibilo. Existe un número ingente de libros que analizan desde distintas perspectivas -políticas, ideológicas, antropológicaslas causas y los efectos del genocidio, aunque debido a la cantidad de testimonios recogidos nos inclinamos por los textos de Linda Melvern, Un pueblo traicionado. El papel de Occidente en el genocidio de Ruanda, y los de Philip Gourevitch, Queremos informale de que mañana seremos asesinados con nuestras familias, dado que ambos ofrecen una nítida visión panorámica del trauma sufrido por los supervivientes.

Para situar las huellas concretas que rastrea Alfredo Jaar en aquel agosto de 1994 en Ruanda es necesario exponer la cadena de acontecimientos que conducen a tan brutal desenlace. Hasta bien entrado el siglo xx , y por casi cuatrocientos años, Ruanda y su país gemelo, Burundi, habían sido reinos con una estructura social en forma de pirámide, configurada en una jerarquía similar a la feudal. El historiador y ensayista Ryszard Kapuściński retrata de manera meridiana en Ébano la organización de la sociedad ruandesa en la época precedente al período colonial:

«[...] Ruanda está habitada por una sola comunidad, un solo pueblo, el banyaruanda, que se divide en tres castas tradicionales: la de los propietarios de rebaños, tutsis (14\% de la población); la de los agricultores, hutus (85\%), y la de los jornaleros y criados, twa $(1 \%)[\ldots]$ Los tutsis no son pastores ni nómadas, ni siquiera ganaderos. Son dueños de los rebaños, son la casta dominante, la aristocracia» (163-5).

Debido sobre todo a su compleja orografía pero también a la escasez de recursos naturales y su aislamiento del mar, los ruandeses vivieron durante un lapso considerable de tiempo, ignorantes de los imperios coloniales que habían diseccionado el 
continente. De hecho, no fue hasta los años treinta que se acentuaron esos efectos, concretamente con la segregación racial impuesta por los belgas en las cédulas de identidad de los habitantes, donde se inscribía la filiación étnica a la que pertenecía el individuo y con la prevalencia de los tutsis sobre el resto de la población.

Los avatares que condujeron a esa inconcebible catástrofe (en hebreo se dice shoah, השואה) son intrincados y sangrientos: revolución y guerra civil en 1959, independencia de la dominación belga en 1962, exilio de los tutsis a Burundi en 1963 y ulterior invasión a Ruanda por parte de los mismos en 1965, golpe de estado del general Juvénal Habyarimana -perteneciente a la etnia hutu- en 1973 y consecuente dictadura férrea hasta abril de 1994, con la ayuda del gobierno de François Miterrand en 1990 para atajar una insurrección de los tutsis (Kapuściński, passim 166-75; tb. otros). El 6 de abril de 1994 es el punto de inflexión; el avión en el que viajaban el presidente Habyarimana con su homólogo burundés, Cyprien Ntaryamira, es derribado por la oposición tutsi en el exilio, el Frente Nacional de Ruanda. La consecuencia que sigue es la explosión de la violencia, espoleada por la cadena Radio Télévision des Mille Collines afín al gobierno de Habyarimana que persuade a los hutus a exterminar completamente a los tutsis y a todos aquellos que se opusieran al régimen del Parmehutu, incluso los hutus que se negaran a participar en la orgiástica carnicería. Mensajes que iban de la denigración -cucarachas los llaman, inyenzi- a la denuncia, indicando direcciones, matrículas o datos de identidad, lo que facilitaba la localización a la policía o la milicia, quienes reunían a las multitudes en espacios deportivos o iglesias para después asesinarlos. La crueldad de las matanzas era tan indescriptible, como recuerda Roméo Dallaire, exgeneral de la UNAMIR (United Nations Assistance Mission for Rwanda), que:

los Interahamwe [la milicia hutu, en idioma kinyarwanda, 'los que pelean juntos'] tenían la costumbre de asesinar a los niños tutsi delante de sus padres, cortándoles los brazos, uno detrás de otro. Después los degollaban con el machete, dejándolos desangrarse lentamente para, mientras aun estaban vivos, cortarles sus genitales y arrojárselos a sus aterrorizados padres, quienes eran asesinados sin más ceremonia (cit. en Khan 16, la traducción es nuestra).

Pero el machete, junto a martillos y palos, fue el medio utilizado por ambos bandos, pues la facción tutsi en su avance hacia Kigali -la capital- también protagonizó encarnizadas matanzas indiscriminadas. Este fenómeno de súbita violencia irracional, en consecuencia, se sitúa más allá del genocidio. Definido en el artículo II de la Convención para la Prevención y Sanción del Delito de Genocidio (Asamblea General de ONU, resolución 260 A III, de 9 de diciembre de 1948) como:

los actos mencionados a continuación, perpetrados con la intención de destruir, total o parcialmente, a un grupo nacional, étnico, racial o religioso, como tal: a) Matanza de miembros del grupo; b) Lesión grave a la integridad física o mental de los miembros del grupo; c) Sometimiento intencional del grupo a condiciones de existencia que hayan de acarrear su destrucción física, total o parcial; d) Medidas destinadas a impedir los 
nacimientos en el seno del grupo; e) Traslado por fuerza de niños del grupo a otro grupo (Serie Tratados 277).

Ruanda fue una singularidad necropolítica, definida en un horizonte de sucesos tras el cual la cadena de eventos futuros se hace imprevisible. Achille Mbembe afirma que la expresión última del poder reside en otorgar la vida y gestionar la muerte, especialmente en términos de guerra; en sus análisis acuña el término «necropoder» (necropower) para combinar en una insólita mezcla los diagnósticos de la biopolítica foucaultiana junto a los rasgos característicos del tardocolonialismo: para él los muertos se inscriben en una masa amorfa, tan despersonalizados en la muerte como lo estuvieron en vida. La masacre y los cuerpos putrefactos se configuran como un potente aliado de la retórica del horror «[...] -donde un gran número de esqueletos estaban a la vista e, incluso, tal vez exhumados- lo que contrasta, por un lado, es la tensión entre la petrificación de los huesos y su extraña frialdad y, por otro, la insistente voluntad de los mismos de testificar, de querer significar algo» (Mbembe 35; énfasis y traducción nuestros). Entre los dos bandos enfrentados desde tiempos inmemoriales ya no existían diferencias palpables -al menos tan manifiestas que estas se pudieran catalogar como étnicas- sino que entre hutus y tutsis se situaba un hondo y arraigado resentimiento espoleado por los radicales que deseaban exterminar y hacer desaparecer cualquier huella del adversario. No era, por tanto, una guerra en la ya olvidada noción de Von Klausewitz, cuyo fin era desarmar al enemigo, sino un desenlace fatal de aniquilación mutua.

Fue el acto de autodestrucción de un país en cuya complicidad incurrieron las grandes potencias a través de Naciones Unidas. El escritor y ensayista Eric Frattini indica en su documentado libro ONU. Historia de la corrupción que ya en 1991 muchas agrupaciones de derechos humanos que trabajaban en Ruanda alertaron de la existencia de organizaciones paramilitares a las altas instancias de la ONU, Boutros-Galli y Kofi Annan, entre otros, hicieron caso omiso de estas informaciones; el citado general Dallaire envió un fax fechado el 11 de enero de 1994 expresando la certeza de la inminente catástrofe: «[se] ha revelado que las milicias extremistas hutus interahamwe en campos de entrenamiento [...] sus superiores han ordenado registrar a todos los tutsis que viven en Kigali. El informante sospecha que es para su exterminación (cit. 228-229)».Con estos antecedentes creemos que no es necesario excederse con más cuestiones de índole geopolítica pero sí incidir en la absoluta apatía de las potencias del mundo desarrollado por evitar la masacre en un país pobre y pequeño que quedaba situado muy lejos de sus intereses estratégicos o mercantiles.

\section{LA MIRADA PETRIFICADA O LA INVALIDEZ DE LA IMAGEN}

Si hay alguien que supo pronosticar con exactitud la mutación teratogenética que sufriría el racionalismo decimonónico, fue Francisco de Goya. Los desastres de la guerra (1810-1820) constituyen un tratado universal, aplicable a cualquier tiempo y espacio posteriores, sobre la abyección bélica. Su serie de grabados han servido para 
ilustrar las retóricas del miedo, las secuelas de los supervivientes, la banalidad del mal en definitiva; Auschwitz, Mauthausen, la guerra civil española, Vietnam, Serbia, Abu Graib, la lista es interminable. «Goya muestra muchísimos cadáveres -escribe Todorov-. Los montones de cuerpos desnudos evocan en nosotros las imágenes de los campos de concentración (Zoran Music, al salir de Dachau, decía que solo podía encontrar una imagen de lo que había vivido Goya)» (120; véase también Bozal 27-39). Queremos llamar la atención con este enfoque de Goya sobre el asunto del mostrar lo irrepresentable, pues en el Rwanda Project de Jaar, de hecho, hay muy poco que ver, dado que todo se encuentra unificado bajo un manto de silencio y de oscuridad, no hay percepción por consiguiente de lo real, solamente lo invisible.

Alfredo Jaar: «Hay un desfase tan grande entre la realidad y lo que uno quiere decir... Pensé que las fotografías no transmitían lo que yo quería y terminé utilizándolas, sin mostrarlas». En esta frase extraída de una entrevista realizada con motivo de la muestra Hágase la luz en el centro de arte Koldo Mitxelena de Donosti (tras haberse expuesto el año anterior en The Light Factory Contemporary Museum of Photography and Film, en Carolina del Norte, con el título Let there be the light), se hace patente la dificultad del artista para concebir un modelo de representación que no resultara ofensivo para con las víctimas de la brutal matanza; es en sí una declaración de principios. En 1987, mucho tiempo atrás con This is not America Jaar continuaba apegado a la utilización de la paradoja mediante el mecanismo de «interpelar al espectador con las tácticas de la comunicación de masas y las formas inmateriales del arte contemporáneo» (Speranza 48). En otros términos, que usaba la demostración tautológica del arte conceptual para expresar lo evidente y manifiesto. Sin embargo, en Rwanda Project toma conciencia de lo difícil, por no decir imposible, que se torna la reconstrucción de hechos tan irracionales como los acaecidos en Ruanda, así titulará una de sus obras, It is difficult, siguiendo un poema de William Carlos Williams (1883-1962): «Es difícil / sacar noticias de un poema / pero los hombres todos los días / mueren miserablemente por no tener aquello que tienen / los poemas».

Apenas un mes más tarde de que las tropas francesas hubieran estabilizado Kigali y el gobierno hutu hubiera huido a la República del Congo -antes Zaire- el 18 de julio (Frattini 237), Jaar llega a Kigali en agosto de 1994 acompañado de su asistente Carlos Vásquez e impelido de una fuerte voluntad de saber y comprender cómo se había llegado a tan infernal situación. El artista recoge con su cámara más de tres mil fotografías y no sabe qué hacer con ellas: todavía no puede asimilar que «la verdad de la tragedia estaba en los sentimientos, palabras e ideas de aquella gente, y no en las imágenes» (cit. en Levi Strauss).

Es posible sospechar que la idea de una obra multifacética de diversos formatos pero al mismo tiempo unitaria no se perfilara en Jaar hasta finales del año 1996, pues no será sino en el año siguiente que presente por primera vez el título The Rwanda Project en la galería Thomas Schulte de Berlín. A pesar de estar abrumado 
por el volumen de imágenes que había registrado, el artista comenzó a experimentar con algunas ideas ya en el mismo año 1994. La primera de ellas en propio territorio ruandés. Jaar compró todas las postales que pudo encontrar -alrededor de unas doscientas- en una oficina de correos de Kigali, las cuales mostraban fotos de promoción turística del país: fauna autóctona, paisajes y danzas, elementos estereotípicos para remarcar la noción de «africanidad» en el inconsciente occidental; Jaar comenzó a enviarlas a amigos y colegas artistas de todo el mundo a medida que iba encontrándose con supervivientes. En ellas escribió siempre el conciso mensaje de «Jyamiya Muhawenimawa is still alive!» (enviada a Luis Cadnitzer) o «Jérome Uwanahoro is still alive!» (enviada a Vinçens Altaió); la obra completa se tituló Signs of Life. Resulta significativa y contradictoria la fuerte discordancia entre ambas caras de la postal, ya que una realidad absoluta que parece increíble dadas las circunstancias -la supervivencia (en sentido superlativo, valga la redundancia- se confronta a la virtualidad del colorido artificial que trata de imponer efectos de verdad inexistentes e ilusorios. La siguiente fue una intervención en el espacio público de la ciudad sueca de Malmö con parte de la serie de cien serigrafías Rwanda Rwanda -el MOMA alberga copia en su colección-, poseían un tamaño de 175 x $118,5 \mathrm{~cm}$ y se ubicaron en el mobiliario urbano destinado a la publicidad. La palabra «RWANDA», escrita con una gruesa tipografía sans serif en color negro, se repetía ocho veces sin dejar traslucir el fondo y creaba un ritmo de formas cercano a las variaciones del op-art de los años sesenta. No obstante, lo más sugestivo de esta obra es la metamorfosis de una imagen en una letanía silenciosa que se materializa auditivamente en la mente del espectador: "RWANDA, RWANDA, RWANDA...» se repite de manera incesante. Alfredo Jaar sabrá aprovechar el alcance de este potente oxímoron, el sonido silencioso en tanto que artificio retórico, en obras posteriores como The Sound of Silence (2006) en cuyo análisis incidiremos más adelante.

Otro de sus trabajos que se integran en esta constelación es Newsweek, donde Jaar se apropia de sus portadas para reforzar su discurso de ambivalencia icónica (ocultación y manifestación) y denunciar, al mismo tiempo, la indiferencia de la revista estadounidense ante el atroz conflicto. La secuencia de textos e imágenes consta de letreros blancos mecanografiados sobre fondo negro con fechas significativas del genocidio de Ruanda, y su contracampo gráfico representado en la portada de esa semana. A medida que se leen los datos confrontados a los que no existen en la revista, se produce una sensación de ritmo in crescendo que resulta inquietante para el espectador, llegándose a sentir la procesión de dichos datos como algo interminable. Un especie de infierno proustiano repetitivo y eterno. Así, el 6 de abril, Jaar anota el suceso del derribo del avión presidencial ruandés junto a la portada con el título «How to Survive in a scary Market», en referencia a la delicada situación bursátil debido al todavía reciente estallido de la burbuja inmobiliaria japonesa o la crisis del mercado de valores en México; el 12 de abril indica que en los primeros cinco días 
han sido asesinadas unas 25.000 personas y yuxtapuesta la portada correspondiente con la foto de Kurt Cobain y la el rótulo «Suicide. Why Do People Kill Themselves?». Como se puede comprobar, el horrible acontecimiento es inexistente para la célebre publicación; otra vez el silencio como elemento modulador.

21 de abril, la ONU reduce las tropas, 50.000 muertos contabilizados; Newsweek habla de las vitaminas. 30 abril, 1.200.000 desplazados, 250.000 refugiados, 100.000 muertos; Newsweek abre con Nixon, recientemente fallecido. 8 de mayo, 200.000 muertos; en portada Nelson Mandela y se alude al «Black Power!». 13-17 de mayo, 30.000 cadáveres en el río Kagera, la ONU autoriza enviar tropas a Ruanda aunque sin fecha firme; portada «Men, Women \& Computers», nimiedades sobre la diferencia de género y la tecnología. 22 de mayo, 300.000 muertos; portada dedicada al Desembarco de Normandía con las celebérrimas instantáneas de Robert Capa, «D-Day. Eyewitness to the Invasion». 26 de mayo, despliegue retrasado por el coste, 400.000 muertos; obituario de Jackie Onassis. 5 de junio, Estados Unidos regatea con la ONU el coste de las fuerzas, 500.000 muertos; portada «The Myth of Generation X». 10 de junio, continua la muerte de tutsis y hutus moderados, incluso en los campos de refugiados, 600.000 muertos; Newsweek prefiere "Virtue. The Crusade Against American's Moral Decline». 17 junio, Francia enviará tropas, 700.000 muertos; Newsweek y «America's Cup. Playing Host to the World». 22 de junio, 800.000 muertos; "Trail of Blood», juicio a O.J. Simpson. 28 de junio-4 de julio, campaña sistemática de genocidio; "Battered Women. Living in Terror», violencia de género. 8 de julio, 900.000 muertos; portada «The Case Against O.J. How Strong?». 12 de julio, un millón y medio de personas huyen a Zaire, 15.000 refugiados cruzan la frontera cada hora, 50.000 muertos por epidemia de cólera en el campo de refugiados de Goma; portada «Korea after Kim. The Headless Beast». 21 julio, la ONU enviará una fuerza internacional, un millón de asesinatos, dos millones de personas han abandonado el país, dos millones de desplazados; portada «To Walk on Mars». 1 de agosto; finalmente, la revista Newsweek dedica por primera vez su portada a Ruanda con el motivo «Hell on Earth. Racing against Death in Rwanda» (cfr. los textos originales en Hágase la luz).

Jaar volverá a esgrimir el razonamiento secuencial como punto fuerte de su argumentación en obras posteriores, ya sea en formato de proyección videográfica o mediante yuxtaposición de cuadros. La contraposición con el montaje alternado de texto e imagen es determinante en obras como Slide + Sound Piece, The Eyes of Gutete Emerita o The Sound of Silence. Aquel fue el procedimiento que Jaar decidió utilizar para enseñar por primera vez imágenes de su viaje. La instalación Let There Be Light (1996) constaba de dos partes bien definidas, a partir de cajas de luz (un sistema muy afín al artista) había una secuencia de nombres iluminados en cada una de ellas: Kigali, Cyangugu, Amahoro, Rukara, Shangi, Mibirizi, Cyahinda, Kibungo, Butare y Gikongoro, la enunciación en una sorda letanía -acompasada únicamente por el zumbido casi inaudible de la alimentación eléctrica- de lugares donde se eje- 
cutaron a miles de personas. La segunda sección son cuatro fotografías proyectadas una detrás de otra, con una suave transición entre ellas, de dos niños que están abrazados. Se les ve de espaldas y es imposible atisbar siquiera que están mirando pues apenas hay profundidad de campo, es un límite exterior difuso pero debe responder a una realidad terrible dada la expresión de los cuerpos de estos pequeños testigos. A diferencia del fotógrafo Kevin Carter (del que hablaremos después) Jaar elige no mostrar y así, toda la potencia se centra en la expresión contenida, en la sugerencia, en la manifestación de un pathos que posee efecto de verdad. Susan Sontag, en su excelente ensayo Ante el dolor de los demás, analiza este tipo de cuestiones; lo que dice sobre Tres Guineas, de Virginia Woolf, se puede extrapolar aquí:

«No condolerse con estas fotos, no retraerse ante ellas, no afanarse en abolir lo que causa semejante estrago, carnicería semejante: para Woolf esas serían las reacciones de un monstruo. [...] Nuestro fallo es de imaginación, de empatía: no hemos sido capaces de tener presente esa realidad» (14-15).

Se configura, pues, un intenso diálogo entre el ellos, que la fotografía concibe como un objeto, y el nosotros, Jaar se afana en que aquella empatía de la que habla Sontag haga mella en el espectador y sea capaz de percibir al sujeto que ha estado allí, al testigo excepcional del acontecimiento. La secuencia del abrazo de los niños dura unas décimas de segundo pero ha conseguido captar en su esencia fraternal un momento infinito y suspendido en el tiempo.

El artista parece buscar una respuesta sobre el procedimiento para expresar aquello que es irrepresentable al tiempo que experimenta sin intermisión sobre cómo ha de exponerlo. Una de estas tentativas cristaliza en Real Pictures, una instalación en el Museum of Contemporary Photography de Chicago en 1995, propuesta donde anuda la despersonalización objetiva del minimal más canónico con la producción de un significado legible en una entidad irracional -el genocidio-. Eligió quinientas cincuenta fotografías que depositó en cajas negras con un texto en su cubierta superior escrito en letras blancas; esos cofres apilados en paralepípedos evocaban las estructuras primarias de Robert Morris, Sol LeWitt o Tony Smith. Disposiciones similares a esta se encuentran en obras tan alejadas entre sí como son el Holocaust Denkmal de Berlín de Peter Einsenman (2005) o 3.000 buecos de $180 \times 70 \times 70$ de Santiago Sierra (2002). Aunque Jaar intenta describir de la manera más sobria posible sus textos están impregnados de un cierto aire de poesía traumática difícil de soslayar:

Gutete Emerita, de 30 años, está delante de la iglesia. Va vestida con ropa modesta y gastada, y lleva el pelo escondido bajo un pañuelo de algodón rosa. Estaba asistiendo a misa cuando empezó la matanza. Mataron ante sus ojos con machetes a su marido, Tito Kahinamura (40 años), y a sus dos hijos, Muhoza (10 años) y Matirigari (7 años). Por puro milagro, consiguió escapar con su hija Marie-Louise Unumararunga (12 años), y estuvo escondida durante tres semanas en una zona pantanosa, de donde solo salía de noche en busca de comida. Cuando habla de la familia que ha perdido, hace gestos hacia los cadáveres del suelo, que se descomponen bajo el sol africano. 
Real Pictures compone un silencioso memento mori donde las palabras suplen a las imágenes que se hallan sepultadas bajo el peso de los contenedores. Con este acto Jaar parece decir que una imagen ya no vale mil palabras, sino todo lo contrario; que la creación posAuschwitz debe basarse en la eliminación del sentimiento y en la búsqueda del testimonio; y que dar fe de lo ocurrido implica situarse en un estado intermedio entre la realidad física y la absurdo de lo infernal.

La superviviente Gutete Emerita es, asimismo, la protagonista de tres versiones distintas de la obra. La motivación de Jaar para ello -como comprobará el lector seguidamente- se inscribe en primera persona al final del siguiente texto. En la primera de las versiones, Alfredo Jaar montó dos pantallas quadvision que proyectaban la sucesión de seis textos y una imagen (dividida en dos por los monitores). La descripción en blanco sobre negro es la que sigue, proyectada en períodos de cinco frases a intervalos de treinta segundos:

En 1994, en un período de cinco meses, más de un millón de ruandeses, en su mayoría integrantes de la minoría tutsi, fueron asesinados de forma sistemática, mientras el mundo cerraba los ojos ante el genocidio. Las matanzas fueron llevadas a cabo principalmente por las milicias hutus, armadas y entrenadas por los militares ruandeses. Un domingo por la mañana, en una iglesia de Ntarama, cuatrocientos tutsis fueron asesinados por un escuadrón de la muerte hutu. Gutete Emerita, de 30 años, estaba en misa con su familia cuando empezó la masacre. A Tito Kahinamura, marido de Gutete y a sus dos hijos, Muhoza y Matirigari, los mataron a machetazos en su presencia. Por alguna razón, Gutete pudo escapar con su hija Marie-Louise Unumararunga. Tras pasar varias semanas escondida, Gutete ha vuelto a la iglesia del bosque. Cuando habla de la familia que ha perdido, hace gestos hacia los cadáveres del suelo, descomponiéndose bajo el fuerte sol africano. Recuerdo sus ojos. Los ojos de Gutete Emerita (cit. en Levi Strauss).

Tras la narración muda -cuyos ecos continúan en la mente del visitante debido a la acción de la oscuridad y la blancura de las grafías- emergen súbitamente los ojos de Gutete, uno en cada pantalla. Pero tal foto es una imagen fragmentada; con un encuadre en primerísimo primer plano el objeto representado son los ojos de la protagonista. Jaar realiza un proceso metonímico de sinécdoque pars pro toto para expresar el testimonio de la superviviente: el espectador se asoma a los órganos que han registrado la trágica y delirante realidad autónoma, que la han visto pero que, a diferencia de la sentencia de Goethe, no han podido comprenderla. Resulta sugestivo que Jaar haya cerrado tanto el encuadre, dejándolo casi borroso, atomizando, gracias al grano sobredimensionado del negativo, la visión del conjunto que se aproxima a algo nebuloso. Las imágenes han quedado retenidas en la leve lámina que separa el individuo del mundo, sin posibilidad de escapar ni de ser concebidas de ninguna manera, absolutamente inefables. Y sin embargo, Jaar ubica continuamente las bases de su discurso en los confines de la oralidad -diferida y transformada en eco en la mente del visitante- y obliga quien se enfrenta a la obra a preguntarse sobre aquello que queda oculto bajo el testimonio. Conviene insistir en que la acción de recordar, en el conjunto de la obra de Jaar, equivale 
a no olvidar; la memoria se produce (y reproduce) indefinidamente. No cesa, es decir, no termina, el acto de traer al presente (representar) las imágenes y en este aporte la memoria y el tiempo se solidifican, lo que permite al artista rescatar, fragmentar y dirigir la mirada externa y ajena del intérprete.

En la siguiente revisión de la obra, también del año 1996, Jaar ciega al espectador en una primera fase con el mismo texto antes citado, pero en esta ocasión configurado en una larga línea en negro sobre blanco para posteriormente, en un inesperado giro de la secuencia de elementos, se encuentre ante una instalación formada por una mesa gigantesca de revisión de negativos. Sobre ella hay una montaña de diapositivas que el visitante puede comprobar con ayuda de un cuentahílos, la misma fotografía se ha replicado en varios miles: los (aquellos) ojos de Gutete que Alfredo Jaar no puede (no quiere, no debe) olvidar. Conviene recalcar la importancia de la repetición y cómo esta modula y vertebra el contenido de la obra: ya el artificio del texto inscrito en el fondo negro (que el artista seguirá utilizando periódicamente) produce una visión residual en la percepción del espectador, una imagen latente que continuará vibrando en el centro de su retina durante varios instantes posteriores a su exposición inicial; por otra parte, la duplicación indefinida de la imagen tiene un calculado efecto metonímico porque los ojos de Gutete Emerita son la pars pro toto que se refiere a la población ruandesa, al tiempo que la masa indefinida de la imagen repetida, paradójicamente, forma una configuración diferente cada vez que se toma una diapositiva para compararla con cualquier otra. The Eyes of Gutete Emerita es una incansable máquina de visión deleuziana que funciona a través de la diferencia y la repetición.

Pese a no estar inscrita en el contexto de las obras sobre Ruanda The Sound of Silence (2006, 2011), esta es una obra que tiene rasgos comunes con él, dado que se sintetiza y se resume la problemática de la representación y lo representable derivada del dilema de las cuestiones ético-estéticas del arte político sincronizadas con la práctica ideológica. Esta instalación utiliza de nuevo la combinación de volúmenes nítidos, iluminación expresiva y una proyección videográfica cuya estructura narrativa es, básicamente, una película muda ( $9 \mathrm{~min}$.) con múltiples intertítulos encadenados y una única imagen. Jaar describe la vida del reportero de prensa surafricano Kevin Carter $^{1}$ a través de sus acontecimientos personales y los sucesos históricos en Suráfrica, intercalando contrapuntos repetitivos. Como en trabajos anteriores, The Sound of Silence conjuga la formulación de los enunciados con la tendencia al minimalismo y la repetición. La lectura de los textos se traduce en la mente del espectador en una parsimoniosa letanía cuyo eco se sincroniza con la imagen residual que dejan las palabras al desaparecer del fondo negro, creando una intensa sensación casi alucinatoria cuando el nombre de Kevin se repite tenazmente.

\footnotetext{
Carter fue el autor de la celebérrima fotografía de un niño sudanés de poca edad tras el que había un buitre expectante; publicada el 26 de marzo de 1993 en el diario New York Times, en pocos días su difusión fue casi total y el fotógrafo ganó el premio Pulitzer en la edición de 1994. Carter no pudo asimilar ni la fama ni las implicaciones éticas que había alcanzado su acción y, ese mismo año 1994, se suicidó pidiendo perdón por la fotografía.
} 
En cuanto a su disposición formal, la instalación está integrada por un gran cubo de aluminio cuya cara frontal está revestida con docenas de tubos fluorescentes, que ciega al visitante y lo fuerza a rodearlo con rapidez para llegar a su cara posterior por donde se accede a una reducida sala de proyección.

Tras la peregrinación de las palabras llega un final artificioso y algo teatral con la inclusión de la fotografía registrada por Carter. Como en otras obras ya citadas, Jaar se aprovecha de la imagen residual procedente de una larga exposición y deslumbra -literalmente- al visitante con un fogonazo que evoca los antiguos flashes de magnesio. Una interpretación posible es que con ese cierre espectacular el espectador comprenda que es cómplice del disparo que captura la realidad (específicamente, la fracción de la realidad: aquí el encuadre es también una cuestión de moralidad). Otra glosa a este trabajo se puede anotar en que hay dos etapas metafóricas de supresión de los sentidos: en la primera, el espectador queda ciego; tras la revelación, enmudece. Jaar manipula los elementos primarios de la comunicación: emisión, recepción y canal son los andamios de un discurso incómodo (y desgraciadamente necesario) sobre lo visible y lo invisible. Merece la pena detenerse en las últimas frases que, a modo de remate, sentencian la paradoja: «los derechos de esta fotografía son gestionados por Corbis / Corbis es propiedad de Bill Gates / Corbis es la agencia fotográfica más grande del mundo / Corbis controla cerca de 100 millones de fotografías / el número de referencia de esta fotografía es corbis 0000295711-001 / nadie sabe qué pasó con el niño / fin» (transcripción directa de la obra, galería Oliva Arauna, Madrid, 2010).

\section{EPÍLOGO-CIERRE (O CÓMO EL SILENCIO DISLOCA LOS ESTRATOS DE LO VISIBLE)}

A la vista de todas estas muestras es inevitable pensar que la entidad "África» es una concepción artificial, parcial y alterada genéticamente para servir a los intereses de los dominadores; incluyendo en esa área imprecisa de elementos de dominación la compostura bienintencionada de un artista como Alfredo Jaar, dado que, en cierto modo, el producto (la obra de arte como mercancía) se ha generado por unas condiciones específicas -el genocidio de Ruanda- y de él se derivarán una serie de plusvalias materializadas en contratos, exposiciones, publicaciones (incluyendo este artículo) u otras de similar índole.

Eludimos la responsabilidad de haber fundado y después, haber privilegiado y perpetuado una imagen de África a nuestro servicio y en nuestro beneficio, cada vez más alejada de su mera posibilidad física. A través del privilegio de las estructuras raciales se fomenta la diferencia de estatus y mediante la construcción de barreras invisibles (aunque en el caso del apartheid en Sudáfrica eran bien manifiestas) se establecen dispositivos de control férreos e indestructibles. A todo ello, y de manera generalizada en esa estereotipada África negra, contribuyó el fomento de la imagen del salvaje sin cultura tecnológica cuya sumisión total debía ofrecerse a la civilización occidental; 
también el capital humano motivado por la demanda de esclavos influyó a la hora de presentar una imagen animalizada e infantilizada de los africanos. Por añadidura, el devenir de las independencias en los procesos de descolonización supuso violentas consecuencias en forma de guerras civiles con el consiguiente beneficio para los paises occidentales que tenían ante sí un extenso mercado para sus armas obsoletas. Así, los nombres de países como Sierra Leona, Angola, Liberia, Biafra, Etiopía, República del Congo, Sudán o Ruanda son sinónimos de hambrunas, corrupción, dictaduras, mortalidad infantil, catástrofe humanitaria, violaciones masivas y sida. África, a pesar de su potencial, es la simbolización del fracaso del Estado moderno en una diferida y crónica lucha por el desarrollo. A fin de cuentas, y tras nuestro estudio, deducimos que Rwanda Project se ha diseñado como un gigantesco atlas que intenta describir los pormenores, los detalles y las aristas del fracaso humanista, tal y como se entendía este en tanto que ideal máximo al que aspiraba la cultura en su proceso civilizador.

Para concluir diremos que cada vez resulta más frecuente encontrar trabajos de arte contemporáneo que utilizan estrategias que conciertan la metáfora y la metonimia con procedimientos que establecen mecanismos de invisibilidad en su discurso; podríamos decir que es una tendencia, sobre todo en obras que tienen un trasfondo político e ideológico muy intenso, a disolver o eliminar aquello de lo que se está hablando para enfatizar aún más su carga semántica. El caso de Jaar de no es aislado, aunque desde luego es uno de los pioneros. Ejemplos de esta senda se pueden rastrear en obras como En el aire (2003), donde Teresa Margolles ejecuta una rutina de desaparición absoluta: en una estancia vacía micropulveriza continuamente el agua resultante de haber lavado cadáveres en el Servicio de Medicina Forense de México D.F., cuerpos de personas que han fallecido en circunstancias extremadamente violentas o que se han suicidado. La sensación es de algo invisible pero al mismo tiempo tangible aunque sea a un nivel molecular. Con estas acciones Margolles denuncia la imparable sangría de hombres y mujeres en Ciudad Juarez, Sinaloa o Tijuana, epítomes de la violencia de género, el narcoterrorismo o la injusticia fronteriza. Más conocida es, sin duda, la intervención de Santiago Sierra en el espacio expositivo de la antigua Sinagoga de Stommeln, $245 \mathrm{~m}^{3}$ (2006), una instalación donde seis coches en el exterior, cuyos tubos de escape estaban conectados directamente con una de las estancias del edificio, bombeaban los gases a la habitación; a la cámara podía acceder el visitante con las necesarias medidas de seguridad (máscara, vestimenta adecuada, tiempo máximo, etcétera). La obra fue censurada y tres días después se cerró al público.

De nuevo, el significado o, mejor dicho, la evocación de este, constituye un poderoso constructor de imágenes en el inconsciente del espectador que asiste en soledad y acompañado únicamente del sonido de su respiración a la representación del teatro del horror. Las palabras del apátrida Emil Cioran en Breviario de podredumbre -utilizadas por Jaar en una versión de Slide + Sound Piece- bien pueden acompañar, a modo de epílogo esperanzador, el cierre de nuestro texto: «Estoy 
exaltado y deprimido, desbordado por el placer y la desesperación en la más contradictoria de las armonías [...] Aunque sea solamente por la alegría de mi tristeza, querría que no hubiera más muerte en esta Tierra».

\section{REFERENCIAS}

Bozal, Valeriano, «La barbarie corriente». El tiempo del estupor. Madrid: Siruela, 2004. Medio impreso.

Didi-Huberman, Georges, «La emoción no dice 'yo'. Diez fragmentos sobre la libertad estética». Alfredo Jaar: La política de las imágenes. Ed. Nicole Schwaizer. Santiago de Chile: Metales Pesados, 2008. Medio impreso.

Frattini, Eric, ONU. Historia de la corrupción. Madrid: Atanor, 2011. Medio impreso.

Gourevitch, Philip, Queremos informale de que mañana seremos asesinados con nuestras familias. Barcelona: Debate, 2009. Medio impreso.

Jar, Alfredo. Alfredojar.net. «The Rwanda Project 1994 - 2000». «http://www.alfredojaar.net». Sitio web.

Kapuściński, Ryszard, Ébano. Barcelona: Ediciones Folio, 2004. Medio impreso.

Khan, Shaharyar M., The Shallow Graves of Rwanda. Nueva York: I.B. Tauris \& Co., 2001. Medio impreso.

Levi Strauss, David, «Un mar de penas no es un proscenio. Acerca de los Proyectos sobre Ruanda de Alfredo Jaar». Hágase la luz: Rwanda Project 1994-1998 (cat.). Barcelona: Actar, 1998. Medio impreso (sin numeración en las páginas).

Mbembe, Achille, «Necropolitics», Public Culture, vol. 15, núm. 1 (2003), 11-40. Medio impreso.

Melvern, Linda, Un pueblo traicionado. El papel de Occidente en el genocidio de Ruanda. Barcelona: Intermón Oxfam, 2007. Medio impreso.

Monegal, Antonio (comp.), Política y (po)ética de las imágenes de guerra. Barcelona: Paidós/Universitat Pompeu Fabra, 2007. Medio impreso.

Sontag, Susan, Ante el dolor de los demás. Barcelona: Mondadori, 2010. Medio impreso. Speranza, Graciela, Atlas portátil de América Latina. Arte y ficciones errantes. Barcelona: Anagrama, 2012. Medio impreso.

Todorov, Tzvtan, Goya. A la sombra de las Luces. Barcelona: Galaxia Gutenberg, 2011. Medio impreso.

VV AA, Serie Tratados de Naciones Unidas no. 1.021, vol. 78. Medio impreso.

Nota: Desde el sitio web que aloja a «The Rwanda Project», se hace referencia a las siguientes obras, ordenadas cronológicamente: 